\title{
Insights into reproduction and behavior of the smalltooth sawfish Pristis pectinata
}

\author{
Kevin A. Feldheim ${ }^{1, *}$, Andrew T. Fields ${ }^{2}$, Demian D. Chapman ${ }^{3}$, Rachel M. Scharer $^{4}$, \\ Gregg R. Poulakis ${ }^{4}$
}

\author{
${ }^{1}$ Pritzker Laboratory for Molecular Systematics and Evolution, The Field Museum, Chicago, Illinois 60605, USA \\ ${ }^{2}$ Institute for Ocean Conservation Science, School of Marine and Atmospheric Science, Stony Brook University, Stony Brook, \\ New York 11794, USA \\ ${ }^{3}$ School of Environment, Arts and Society, Florida International University, North Miami, Florida 33181, USA \\ ${ }^{4}$ Fish and Wildlife Research Institute, Florida Fish and Wildlife Conservation Commission, \\ Charlotte Harbor Field Laboratory, Port Charlotte, Florida 33954, USA
}

\begin{abstract}
Sawfishes (Family Pristidae) constitute one of the most threatened families of marine fish, and substantial management efforts are required to stabilize and recover their populations worldwide. Philopatry is common in marine animals, including sharks and rays, and can be a key driver of population structure, which in turn determines the most appropriate scale required for effective population assessment and management. We examined philopatry at 2 known smalltooth sawfish Pristis pectinata nursery sites in the Charlotte Harbor estuarine system, Florida (i.e. Caloosahatchee and Peace rivers) by reconstructing parental genotypes based on composite genotypes from dorsal fin clippings of offspring captured within the nurseries between 2004 and 2015. Of 55 reconstructed females, 45 clearly exhibited philopatry to these nursery sites, most on a biennial cycle. Thirty-four females gave birth in the Caloosahatchee River, 19 gave birth in the Peace River, and 2 females used both nurseries for parturition. Nine females have been giving birth at these sites for a decade or more. Two females produced offspring with the same male over consecutive breeding seasons and one other pair of parents was identified at a 6 yr interval, suggesting that females store sperm, use an unknown mating aggregation site, or both. Male genotypes $(n=192)$ were rarely seen more than once at these nurseries $(n=7)$. However, some males mated in consecutive years, and successfully with multiple females within years. Evidence of parturition site fidelity by smalltooth sawfish in Florida likely extends the time before range expansion would be expected.
\end{abstract}

KEY WORDS: Philopatry · Polyandry · Parthenogenesis · Management · Mating systems · Conservation

\section{INTRODUCTION}

The sawfishes (Family Pristidae) constitute one of the most threatened families of marine fish in the world, and substantial management efforts are required to stabilize and recover their populations worldwide (Dulvy et al. 2016). Important questions remain about the population structure and ecology of sawfishes worldwide that need to be answered to establish population baselines, monitor population

${ }^{*}$ Corresponding author: kfeldheim@fieldmuseum.org trajectories over time, and develop effective management practices. Modern genetic techniques are at the forefront of answering some of these questions, and some, such as environmental DNA, hold promise for identifying the presence of sawfishes in the most remote or especially low population regions (Feutry et al. 2015, Simpfendorfer et al. 2016 this Theme Section, Poulakis et al. 2017 this Theme Section).

One question of interest often examined using genetic approaches is to assess philopatric behavior.

(C) The authors 2017. Open Access under Creative Commons by Attribution Licence. Use, distribution and reproduction are unrestricted. Authors and original publication must be credited.

Publisher: Inter-Research · www.int-res.com 
Philopatry has been defined as the propensity of individuals to remain within or return to their natal area, home range, or another adopted locality (Mayr 1963). Philopatry is common in marine animals, including sharks and rays, and can be a key driver of population structure, which in turn determines the most appropriate scale required for effective population assessment and management (Hueter et al. 2004, Chapman et al. 2015, Flowers et al. 2016). Little is known about philopatry in sawfishes, hindering management of the group (Flowers et al. 2016).

Some female sharks and rays have been shown to practice a type of philopatry known as 'parturition site fidelity', whereby individuals regularly return to the same parturition site to give birth (Chapman et al. 2015). In some cases, this return location is the same place where the individual was born, which is known as 'natal philopatry', leading to intergenerational use of the same birthing locations (Feldheim et al. 2014, Chapman et al. 2015). Both of these types of philopatry have strong management implications because every parturition site is used by a subset of the total population and is therefore more vulnerable to localized depletion if anthropogenic stressors such as exploitation are concentrated at that site (Hueter et al. 2004, Chapman et al. 2015). It also means that populations can become genetically structured at finer geographic scales than expected based on the species' dispersal ability, which can lead to local adaptation of individuals to the environmental conditions where they are born (Hueter et al. 2004, Chapman et al. 2015). Parturition site fidelity can be demonstrated by showing that the same individuals return to the same site to give birth, whereas natal philopatry requires independent evidence that this is also the individual's birthplace (Chapman et al. 2015). The former can be proven with genetic pedigree reconstruction, which uses the genotypes of a large number of juvenile individuals residing in a particular parturition site to reconstruct the genotypes of their parents (e.g. Feldheim et al. 2002, 2004). If certain reconstructed parental genotypes are encountered over multiple cohorts, it proves that those individuals are returning to this site to breed (Feldheim et al. 2002, 2004). Intergenerational parental reconstruction studies are needed to demonstrate natal philopatry, and as such it often requires more sampling effort, sometimes on decadal temporal scales (Feldheim et al. 2014). Evidence demonstrating parturition site fidelity is often a precursor step to demonstrating natal philopatry.

Although there is evidence of philopatry in Pristis sawfishes in the Indo-Pacific (Phillips et al. 2011, Feu- try et al. 2015), philopatry has not been documented in the Atlantic. The US population of smalltooth sawfish Pristis pectinata has experienced a severe decline and range contraction, from a large population distributed from the mid-Atlantic to Texas, to a population of perhaps a few thousand individuals occurring primarily in southwest Florida (Norton et al. 2012). Within this region, there are 2 discrete nursery areas, which are defined as locations meeting the following criteria: (1) juveniles are more commonly encountered than in other areas; (2) sawfish remain or return for extended periods; and (3) the area is repeatedly used by juveniles across years (Heupel et al. 2007). Parturition occurs within these nursery areas and juveniles rely on them for their early life history, which makes them essential areas for conservation and recovery (Poulakis et al. 2011). The 2 nursery areas currently designated as critical habitat are the Charlotte Harbor Estuary Unit $\left(896 \mathrm{~km}^{2}\right)$ and the Ten Thousand Islands/Everglades Unit $\left(2505 \mathrm{~km}^{2}\right)$ (Norton et al. 2012). To date, there has been no evidence of genetic or demographic separation between sawfish living or visiting these nursery areas (Chapman et al. 2011), so it is unknown if adult sawfish exhibit parturition site fidelity or natal philopatry to one or the other of these nursery areas. The distance separating these 2 nursery areas is well within the known dispersal range of adults (Carlson et al. 2014), so it is possible that females will give birth in either one of them at random. If true, this would mean that a population trend observed in one critical habitat unit would likely reflect that of the entire population, and the 2 nursery areas should be monitored and managed as one large connected unit. Alternatively, it is possible that individuals do exhibit parturition site fidelity to one nursery area or the other, which would mean that each could have unique, internally driven population dynamics and should both be monitored and managed independently.

Here, we tested the hypothesis that adult female smalltooth sawfish exhibit parturition site fidelity to one of these nursery areas, the Charlotte Harbor estuarine system. We reconstructed parental genotypes from juveniles sampled within this system from 2004 to 2015 . The hypothesis predicts that individual parental genotypes would be found across multiple cohorts.

\section{MATERIALS AND METHODS}

A total of 349 juvenile smalltooth sawfish Pristis pectinata were fin clipped $(\sim 2 \mathrm{~g}$, usually the free 
rear tip of the second dorsal fin) from within the 2 Charlotte Harbor estuarine nurseries between 2004 and 2015 ( $\mathrm{n}=148$ from northern Charlotte Harbor, primarily the Peace River; $\mathrm{n}=201$ from southern Charlotte Harbor, primarily the Caloosahatchee River; Fig. 1). Sawfish at these sites are 671 to 812 $\mathrm{mm}$ stretch total length (STL) at birth (Poulakis et al. 2011). Juvenile sawfish grow rapidly, doubling in length in their first year of life (Simpfendorfer et al. 2008, Scharer et al. 2012). Size at maturity is unknown, but has been estimated to be $340 \mathrm{~cm}$ STL for males and $380 \mathrm{~cm}$ STL for females (R. D. Grubbs \& J. Gelsleichter unpubl. data). Currently, the best estimate for brood size is from the number of large follicles ( 7 to 14 ) observed during necrop-

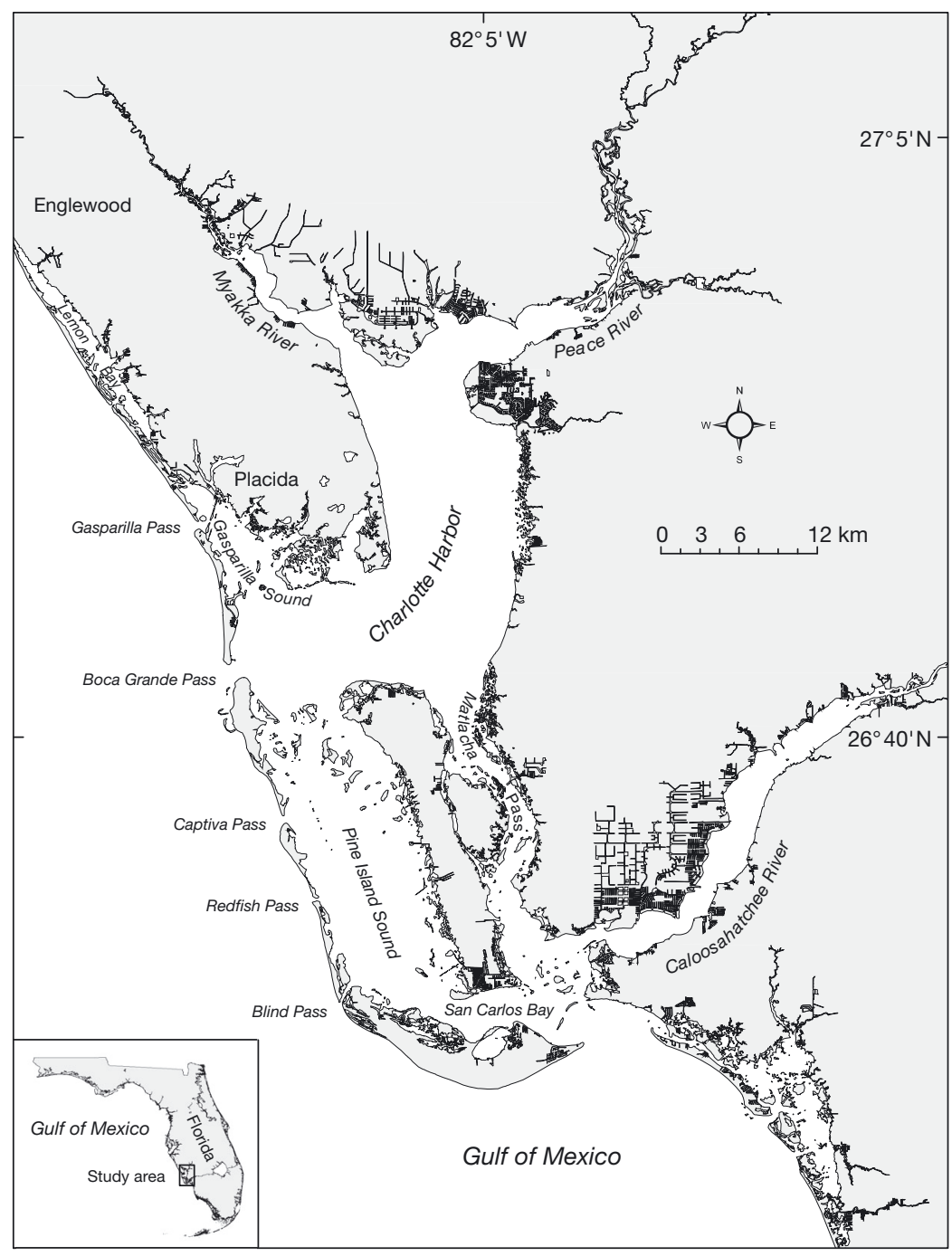

Fig. 1. Charlotte Harbor estuarine system, Florida. Northern Charlotte Harbor (especially the lower Peace River) and southern Charlotte Harbor (especially the Caloosahatchee River) are distinct nursery areas for the smalltooth sawfish Pristis pectinata (Poulakis et al. 2011) sies of non-gravid adult females (G. R. Poulakis \& J. Gelsleichter unpubl. data).

Most of the samples were collected during random or directed sampling for juvenile smalltooth sawfish; a few were obtained opportunistically from other sources (e.g. necropsies). Monthly random sampling was conducted year-round in the Caloosahatchee River from 2004 to 2009 using a $183 \mathrm{~m}$ haul seine. From 2010 to 2015, between February and September in the Caloosahatchee and Peace rivers, random sampling was conducted using a 30.5 or $61 \mathrm{~m}$ gill net with 102 mm stretch monofilament mesh. Random gill net sampling was proportional to nursery area size (Peace River area: 8 sites $\mathrm{mo}^{-1}, 2$ nets site ${ }^{-1}$; Caloosahatchee River: 6 sites $\mathrm{mo}^{-1}, 2$ nets site $^{-1}$ ). Monthly directed sampling (i.e. targeting smalltooth sawfish) was initially conducted year-round using a multi-gear approach (2004 to 2009), then primarily between February and September (2010 to 2015). An average of 4 directed sampling trips were conducted each month, 2 in each nursery. Gill nets were mainly used for directed sampling during the entire study period and were typically soaked for $1 \mathrm{~h}$. When water clarity was favorable, we actively searched for sawfish and used gill nets to catch any detected animals. The lengths of sampled individuals ranged from 671 to $2187 \mathrm{~mm}$ STL, but the majority (70\%) of sawfish sampled were young-ofthe-year. We assigned birth years based on peak recruitment months and known growth rates (Poulakis et al. 2011, Scharer et al. 2012).

DNA was extracted from all sampled individuals using a salting out protocol (Sunnucks \& Hales 1996) or the DNeasy tissue kit (Qiagen). A total of 15 microsatellite loci were used to genotype every individual (Feldheim et al. 2010, Fields et al. 2015). The loci (up to 40 alleles locus ${ }^{-1}$ ) have been used in previous studies to examine population genetics (Chapman et al. 2011) and parthenogenesis (Fields et al. 2015) in these populations. All loci were in Hardy-Weinberg equilibrium and exhibited linkage equilibrium. To examine the mating system at these sites, we employed COLONY v.2.0 (Wang 
2004, Jones \& Wang 2010). Colony groups individuals into sibling groups and reconstructs parental genotypes based on composite genotypes of offspring. Three Colony runs were performed. In each run, allelic dropout was set at 0 , and error rate was set at $0.5 \%$. For the first 2 runs, mating system was set to polygamy for females and monogamy for males. Half-sibship in these first 2 runs was assumed to be through the mother. This assumption was based on studies of other elasmobranchs that have found that females tend to mate polyandrously (Portnoy \& Heist 2012), resulting in maternal half-siblings within years. Additionally, many female elasmobranchs return to nursery areas for parturition (Chapman et al. 2015), so maternal half-siblings across years will be due to philopatric females. This approach is based on the assumption that it is much more likely that broodmates are sampled (i.e. maternal half-siblings) rather than sampling offspring from different females that happened to mate with the same male (i.e. paternal half-siblings).

Results from the first run were analyzed by eye for each sibling group, and female genotypes were reconstructed manually (Feldheim et al. 2004) using the reconstructed female genotype output in COLONY as a guide. When possible, male genotypes were also reconstructed manually. Results from the second run were compared to the first. Any discrepancy between runs typically resulted in the sibling group being excluded from further analyses. Exceptions occurred when one run had a sibling group in $90 \%$ or more of simulations (i.e. we kept a sibling group intact when it was reconstructed in $90 \%$ of simulations in at least one run).

'Forcing' males to be monogamous for analysis purposes precluded identifying those males that were promiscuous. As a result, to determine whether any males mated polygamously, we ran COLONY a third time using the parameters described above, with the exception that mating system was set to polygamy for both sexes. In addition, we included reconstructed female $(n=22)$ and male $(n=25)$ genotypes from the first 2 runs as candidate parents for the third run.

\section{RESULTS}

Colony results were used to infer characteristics of the smalltooth sawfish Pristis pectinata mating system and breeding biology at these Florida nursery sites. ColonY reconstructed 74 and 71 female genotypes for the first and second runs, respectively. Of those, 55 were either identical between runs $(n=50)$ or were reconstructed in $90 \%$ of simulations $(n=5)$ in one of the analyses. These 55 females gave birth to a total of 142 broods (Fig. 2). Of those 142 broods, 13 were the result of polyandrous mating. This estimate of polyandry may be low due to the fact that most broods $(\mathrm{n}=117)$ were only composed of 3 or fewer pups. Of the 55 females, $82 \%(n=45)$ clearly exhibited philopatry, most on a biennial cycle, to these nursery sites (Fig. 2). The other 10 females were only present in a single year and of these, 2 gave birth early in the study and 8 were detected in the last $5 \mathrm{yr}$, so they may be philopatric outside of the sampling period. Thirty-four females gave birth only in the Caloosahatchee River, 19 gave birth only in the Peace River, and 2 females used both nurseries for parturition (Fig. 2). Nine females (5 to 8, 10, 38, and 41 to 43 ) have been giving birth at these sites for a decade or more (Fig. 2). The highest number of siblings from an individual female in a single year was 8 , which is a conservative estimate of brood size. The maximum number of females that gave birth in $1 \mathrm{yr}$ was 11 (twice) or 12 in the Caloosahatchee River, and 10 (twice) in the Peace River. Similarly, the maximum number of females that gave birth in both nurseries combined in a single year was 17 (2011 and 2014).

CoLONY reconstructed 192 males to account for the 142 broods. Setting COLONY to polygamy for both sexes revealed that some males mated with more than one female (Table 1). Although male genotypes were rarely seen more than once at these nurseries $(4 \%, \mathrm{n}=7)$, some did mate in consecutive years (i.e. male 48) or with multiple females within years (i.e. male 183). Three males in this study remained reproductively active for at least 7 yr (i.e. males 21, 72, and 192). Two females produced offspring with the same male over consecutive breeding seasons. Female 43 had offspring with male 77 in 2011 and again in 2013, and female 15 had offspring with male 126 in 2012 and 2014 .

\section{DISCUSSION}

Philopatric behavior of female elasmobranchs has been hypothesized to occur (Hueter et al. 2004), mainly due to indirect evidence from differences between nursery sites in mitochondrial DNA (mtDNA) markers (Chapman et al. 2015, Flowers et al. 2016). Direct evidence, however, requires either tag-recapture of individual adult females (e.g. Feldheim et al. 2014), sampling DNA from a female and finding her offspring in nurseries through parentage assignment (e.g. Feldheim et al. 2002, Mourier \& Planes 2013), or 


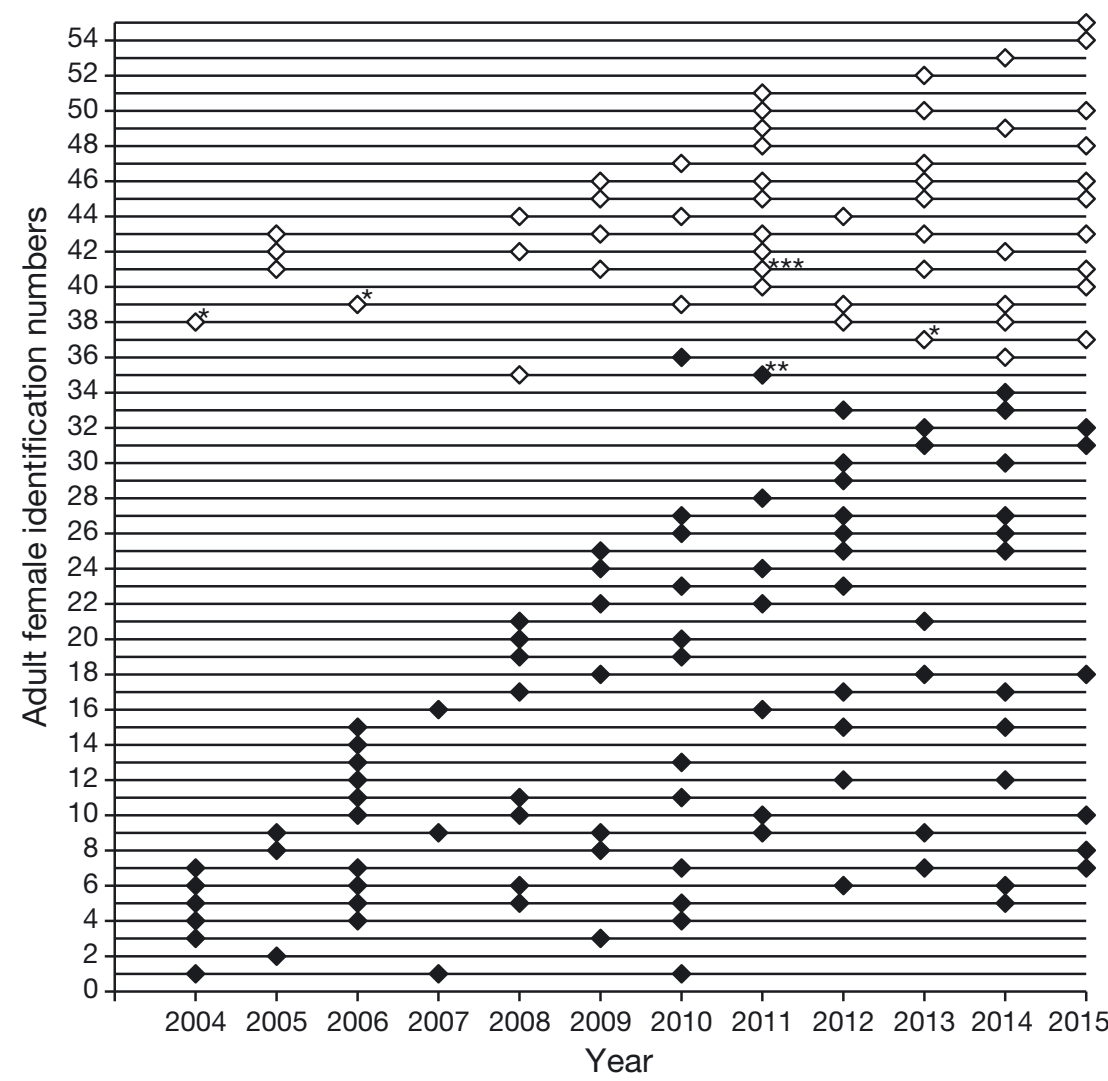

Fig. 2. Philopatric behavior of genetically reconstructed adult female smalltooth sawfish Pristis pectinata at 2 nurseries in the Charlotte Harbor estuarine system, Florida, from 2004 to 2015. A diamond above a year indicates that the female gave birth in that year and that one or more offspring were caught during sampling. : the female gave birth in the Caloosahatchee River (females 1 to 34 ); $\diamond$ : the female gave birth in the Peace River (females 37 to 55). Two females (females 35 and 36 ) used both rivers for parturition. (*) broods represented by 1 large juvenile (see 'Discussion' for details) that we hypothesize was born in the Peace River and moved south to the Caloosahatchee River where it was caught. $(* \star)$ includes 2 small juveniles that were born in the Caloosahatchee River and 1 large juvenile (2380 mm stretch total length, STL) that we hypothesize was born in the Caloosahatchee River and moved south to the Ten Thousand Islands where it was caught. (***) large juvenile $(2130 \mathrm{~mm}$ STL) that we hypothesize was born in the Peace River and moved south to the Ten Thousand Islands where it was caught

genetic reconstruction of female genotypes (e.g. Feldheim et al. 2004). The latter method requires exhaustive sampling of juveniles over many years. Here, we were able to sample enough offspring to characterize philopatry of the endangered smalltooth sawfish Pristis pectinata. Female smalltooth sawfish in the Charlotte Harbor estuary tend to be philopatric, specifically, exhibiting parturition site fidelity, and often mate polyandrously. In similar studies at Bimini, Bahamas, female lemon sharks Negaprion brevirostris were also found to mate with multiple males and exhibit parturition site fidelity (Feldheim et al. 2002), with some females exhibiting natal philopatry to this nursery area (Feldheim et al. 2014).
Our results indicate that female smalltooth sawfish have a biennial reproductive cycle. We found no evidence of any female returning annually to give birth. Although it has been hypothesized that females give birth every other year, this is the first direct evidence (i.e. maternally related sibling groups every second year) of a biennial reproductive cycle for female smalltooth sawfish. Interestingly, some females appeared to give birth every third year (see Fig. 2). There are several possible explanations for this observation: females could not find a mate, they mated with infertile or genetically incompatible males, they gave birth in a non-Charlotte Harbor nursery, they did not acquire the resources necessary to give birth on the normal biennial reproductive cycle, or their offspring were not sampled in a particular year. Another possibility is that our assignment of one (or more depending on the length of the time series) of the birth years of progeny for a given female could have been off by 1 yr, artificially disrupting the biennial pattern. Regardless, this variability was rare and did not obscure the general patterns that were revealed over the $12 \mathrm{yr}$ time series. It is unknown how long female sawfish remain reproductively active, but some females gave birth over the entire course of the study at these sites. Others, however, gave birth only early in the study, suggesting they possibly died or reached reproductive senescence, while others were only observed late in the study, suggesting they had recently matured. Ongoing DNA sampling and analysis, hormone analyses, and opportunistic necropsies of adult females may allow us to determine the length of temporal association of individual females with the individual nurseries and to investigate whether deviations from the biennial reproductive cycle may occur in a portion of the smalltooth sawfish population.

Our assumption of half-sibship occurring through females was initially based on evidence from other elasmobranchs where females exhibit polyandry, which leads to maternal half-siblings within years (Griffiths et al. 2012, Chapman et al. 2013) and 
Table 1. Male smalltooth sawfish Pristis pectinata that mated with more than one female at the Caloosahatchee River (CR) and Peace River (PR) nurseries in Florida. Female identification numbers match those in Fig. 2, with the exception of females 56 to 59 . These females were not reconstructed in either of the first 2 COLONY runs but were reconstructed in the third COLONY run (i.e. when both sexes were set to polygamous, see 'Materials and methods' for details)

\begin{tabular}{|c|c|c|c|c|}
\hline Male & Mated with & $\begin{array}{l}\text { Year of } \\
\text { brood }\end{array}$ & $\begin{array}{l}\text { No. of } \\
\text { offspring }\end{array}$ & Site \\
\hline 21 & $\begin{array}{l}\text { Female } 14 \\
\text { Female } 18\end{array}$ & $\begin{array}{l}2006 \\
2013\end{array}$ & $\begin{array}{l}2 \\
1\end{array}$ & $\begin{array}{l}\mathrm{CR} \\
\mathrm{CR}\end{array}$ \\
\hline 48 & $\begin{array}{l}\text { Female } 56 \\
\text { Female } 43\end{array}$ & $\begin{array}{l}2008 \\
2009\end{array}$ & $\begin{array}{l}1 \\
2\end{array}$ & $\begin{array}{l}P R \\
P R\end{array}$ \\
\hline 72 & $\begin{array}{l}\text { Female } 48 \\
\text { Female } 40\end{array}$ & $\begin{array}{l}2008 \\
2015\end{array}$ & $\begin{array}{l}1 \\
2\end{array}$ & $\begin{array}{l}\text { CR } \\
\text { PR }\end{array}$ \\
\hline 113 & $\begin{array}{l}\text { Female } 12 \\
\text { Female } 57\end{array}$ & $\begin{array}{l}2012 \\
2015\end{array}$ & $\begin{array}{l}2 \\
1\end{array}$ & $\begin{array}{l}\text { CR } \\
\text { CR }\end{array}$ \\
\hline 174 & $\begin{array}{l}\text { Female } 37 \\
\text { Female } 18\end{array}$ & $\begin{array}{l}2013 \\
2015\end{array}$ & $\begin{array}{l}1 \\
2\end{array}$ & $\begin{array}{l}\text { CR } \\
\text { CR }\end{array}$ \\
\hline 183 & $\begin{array}{c}\text { Female } 7 \\
\text { Female } 55\end{array}$ & $\begin{array}{l}2015 \\
2015\end{array}$ & $\begin{array}{l}2 \\
5\end{array}$ & $\begin{array}{l}\text { CR } \\
\text { PR }\end{array}$ \\
\hline 192 & $\begin{array}{c}\text { Female } 7 \\
\text { Female } 58 \\
\text { Female } 59\end{array}$ & $\begin{array}{l}2004 \\
2008 \\
2012\end{array}$ & $\begin{array}{l}3 \\
1 \\
1\end{array}$ & $\begin{array}{l}\text { CR } \\
\text { CR } \\
\text { CR }\end{array}$ \\
\hline
\end{tabular}

philopatry to nursery grounds, which leads to maternal half-siblings across years (Feldheim et al. 2004, Mourier \& Planes 2013). In addition to this support from the literature, we found many groups of half-siblings in alternate years (i.e. a biennial female reproductive cycle), which is a key finding that further supports this approach (Fig. 2). If this biennial half-sibling pattern was due to halfsibship through males, it would mean that these males (1) were only mating every other year and (2) were mating with different females that happen to give birth in the same nursery. Further, if the main pattern was half-sibship through males, we would expect to find many half-siblings in consecutive years, which we did not. It is biologically unrealistic to think that males would only mate with 1 female $\mathrm{yr}^{-1}$, and indeed, using our methodology, we found several males that mated with multiple females (see Table 1). Based on our analysis approach, we were likely to miss some male multiple matings, but we were mainly concerned with the overall pattern of mating by this species. Finally, the genotypes of 3 parthenogenetic females (Fields et al. 2015; see more on these below), were used to verify parentage assigned by COLONY and provide direct evidence of biennial maternal halfsibship. Given these factors, we believe that the pattern of half-sibship across years was due to philopatric females.

Although most adult female smalltooth sawfish exhibited parturition site fidelity to either the Caloosahatchee or Peace rivers, there were 2 females that gave birth in both nurseries (females 35 and 36; Fig. 2). Evidence for this comes from finding age-0 offspring from these females in both nurseries, and from previous research that showed the activity space of this early age- 0 size class $(<1200 \mathrm{~mm} \mathrm{STL})$ to be small enough that they were likely confined to their natal nurseries (Simpfendorfer et al. 2011, Scharer et al. 2012). At first glance, our data indicated that there were 4 additional adult females that may have given birth in both nurseries, but detailed examination of the time series of each of these potential multi-nursery females suggested southerly movements of 5 large juveniles instead (Fig. 2). On the basis of multi-year evidence of age-0 offspring, we hypothesize that 4 of the 5 large juveniles (mean STL $=1687 \mathrm{~mm}$ ) were born in the Peace River and were caught either to the south at the Caloosahatchee River $(n=3)$ or even further south in the Ten Thousand Islands $(\mathrm{n}=1)$. Similarly, based on the presence of 2 age- 0 siblings ( 1 half-sibling and 1 full sibling) from the same estimated birth year, we hypothesize that the fifth large juvenile was born in the Caloosahatchee River and was caught as a large juvenile (2380 mm STL) in the Ten Thousand Islands. Preliminary tag-recapture and satellite tagging data have suggested connectivity between the Charlotte Harbor nurseries and regions of the current range to the south such as the Ten Thousand Islands and the Florida Keys (G. R. Poulakis, P. O'Donnell \& R. D. Grubbs unpubl. data), and the DNA data presented here support those findings. This growing evidence suggests that large juveniles move south after they leave the Charlotte Harbor nurseries and some return as adults. Examining DNA from the entire current range of the species and carefully linking those data to demographic and movement data will be necessary to improve our understanding of the life history patterns identified by this study to determine if similar patterns exist range-wide, and ultimately how these data relate to ongoing recovery planning.

Using our conservative criterion (i.e. we kept a sibling group intact when it was reconstructed in $90 \%$ of simulations in at least 1 run), 2 females were found to produce broods with the same male in consecutive breeding seasons. In addition, one other pair of parents was identified at a 6 yr interval (female 42 and male 11 came out in $88 \%$ of one of the simulations as the parents of full siblings in 2005 and 2011). This 
suggests that the same parents mated on 2 separate occasions, perhaps at a mating ground. For most elasmobranchs, it is unknown whether or not mating grounds exist; however, one well-studied site is the Dry Tortugas, Florida, where nurse sharks Ginglymostoma cirratum mate annually (Pratt \& Carrier 2001). Mating in smalltooth sawfish has never been observed in the wild, and we are uncertain whether or not individuals congregate to mate. Alternatively, these females could have stored the sperm from one mating and subsequently used the sperm to fertilize eggs from different broods. It is unknown whether or not sperm storage occurs in smalltooth sawfish, but it is known to occur in other elasmobranchs (Pratt 1993), and sperm has remained viable for up to 45 mo in a captive female brownbanded bamboo shark Chiloscyllium punctatum (Bernal et al. 2015). If the female smalltooth sawfish that produced full siblings in 2005 and 2011 stored the sperm, it would have almost doubled the longest storage time of viable sperm for any elasmobranch. For this reason, we hypothesize that the full siblings separated by $6 \mathrm{yr}$ resulted from use of an unknown mating aggregation site and that the full siblings separated by only $2 \mathrm{yr}$ resulted from either sperm storage, use of an aggregation site, or both. In a previous study, Fields et al. (2015) showed that 3 females giving birth at these sites did so via facultative parthenogenesis. Females 5, 48, and 50 (Fig. 2) had parthenogenetic broods in 2004, 2011, and 2011 respectively. It is interesting to note that each of these females gave birth to young produced sexually for all other broods (Fig. 2). Switching between reproductive modes has only been shown twice before in elasmobranchs, and only in captivity (Harmon et al. 2016, Dudgeon et al. 2017). These are the first cases of individual females switching reproductive modes in the wild.

Male genotypes were rarely seen more than once at these nurseries. The few males that did sire offspring in more than one brood provide some insight into the reproductive behavior of male smalltooth sawfish. Males can mate in consecutive years (i.e. annually) and with multiple mates within a year. Three males in this study remained reproductively active for at least $7 \mathrm{yr}$. In lemon sharks at Bimini, Bahamas, male genotypes have also rarely been seen more than once over a 20 yr time series (Feldheim et al. 2004, 2014), and these authors have hypothesized that males mate with females from multiple nurseries, keeping nuclear genetic differentiation between populations low despite genetic differentiation in maternally inherited markers (Ashe et al. 2015). Analyzing the mating system of smalltooth sawfish elsewhere in the range will provide insight as to whether or not the same phenomenon (i.e. males mating over a broad range) is occurring in this species. We hypothesize that some of the reconstructed male genotypes from this study, which was conducted at the northern limit of the current range of the species, will be found in parentage analysis of samples from further south (e.g. Everglades National Park).

There is little information on brood size of smalltooth sawfish in the literature, and we found that the maximum number of young we caught from a female in a single year was 8. As we did not catch every sawfish in the nursery (i.e. recapture rates were low), the maximum number of siblings from a given female in a single year is a conservative estimate of brood size. Over the long term, these data, and metrics such as the number of adult females reproducing rangewide, will be useful for fine-tuning recovery models (e.g. Carlson \& Simpfendorfer 2015).

The majority of adult female smalltooth sawfish exhibited philopatric behavior and used one nursery exclusively. This behavior, combined with evidence of differences in habitat use between the Caloosahatchee and Peace rivers (Scharer et al. in press, this Theme Section), will make it important to protect and manage these nursery areas separately to conserve these populations over the long term. In addition, the fact that smalltooth sawfish exhibit parturition site fidelity in Florida, which is often a precursor to documenting natal philopatry (Chapman et al. 2015), has implications regarding range expansion. Because females have an innate association with specific nursery areas, the population may have to recover to high levels to promote the production of females that might travel to nurseries outside the current range to give birth (Hueter et al. 2004). Further, the philopatric behavior of smalltooth sawfish underscores the need for consistent, long-term fisheries-independent monitoring of nursery areas throughout the current range of the species. These data will be necessary to identify long-term population trends as well as potential shorter-term, spatially localized effects of disturbances (e.g. cold events or reports of localities with high numbers of rostrumless sawfish; Scharer et al. in press) and the subsequent need to focus outreach efforts. Like well-known examples of the importance of natal streams for salmon and nesting beaches for sea turtles, smalltooth sawfish are strongly philopatric, and future research should focus on identifying the spatial structure of nurseries where females are giving birth throughout the current range of the species. 
Acknowledgements. This work was supported primarily by funding from the United States Department of Commerce (DOC), National Oceanic and Atmospheric Administration's (NOAA) National Marine Fisheries Service through Section 6 (Cooperation with the States) of the US Endangered Species Act under the following grant awards to the Florida Fish and Wildlife Conservation Commission: from the DOC, NOAA - NA06NMF4720032, NA10NMF4720032, and NA13NMF4720032; from the National Fish and Wildlife Foundation - 2003-0206-008 and 2004-0012-008. The statements, findings, conclusions, and recommendations are those of the authors and do not necessarily reflect the views or policies of the DOC, NOAA, or the National Fish and Wildlife Foundation. Mention of trade names or commercial products does not constitute their endorsement by the US government or the National Fish and Wildlife Foundation. This research was conducted under Endangered Species Permit numbers 1475 and 15802 (FWC) issued by the National Marine Fisheries Service. Genetic data were gathered in the Field Museum's Pritzker Laboratory for Molecular Systematics and Evolution operated with support from the Pritzker Foundation. This work was presented as part of the symposium 'Biology and Ecology of Sawfishes' at the 2016 annual meeting of the American Elasmobranch Society, which was supported by funding from the Save Our Seas Foundation, Disney Conservation Fund, and the American Elasmobranch Society.

\section{LITERATURE CITED}

Ashe JL, Feldheim KA, Fields AT, Reyier EA and others (2015) Local population structure and context-dependent isolation by distance in a large coastal shark. Mar Ecol Prog Ser 520:203-216

Bernal MA, Sinai NL, Rocha C, Gaither MR, Dunker F, Rocha LA (2015) Long term sperm storage in the brownbanded bamboo shark Chiloscyllium punctatum. J Fish Biol 86:1171-1176

Carlson JK, Simpfendorfer CA (2015) Recovery potential of smalltooth sawfish, Pristis pectinata, in the United States determined using population viability models. Aquat Conserv 25:187-200

Carlson JK, Gulak SJB, Simpfendorfer CA, Grubbs RD, Romine JG, Burgess GH (2014) Movement patterns and habitat use of smalltooth sawfish, Pristis pectinata, determined using pop-up satellite archival tags. Aquat Conserv 24:104-117

Chapman DD, Simpfendorfer CA, Wiley TR, Poulakis GR and others (2011) Genetic diversity despite population collapse in a critically endangered marine fish: the smalltooth sawfish (Pristis pectinata). J Hered 102:643-652

Chapman DD, Wintner SP, Abercrombie DL, Ashe J, Bernard AM, Shivji MS, Feldheim KA (2013) The behavioural and genetic mating system of the sand tiger shark, Carcharias taurus, an intrauterine cannibal. Biol Lett 9: 20130003

Chapman DD, Feldheim KA, Papastamatiou YP, Hueter RE (2015) There and back again: a review of residency and return migrations in sharks, with implications for population structure and management. Annu Rev Mar Sci 7: $547-570$

* Dudgeon CL, Coulton L, Bone R, Ovenden JR, Thomas S (2017) Switch from sexual to parthenogenetic reproduction in a zebra shark. Sci Rep 7:40537
Wulvy NK, Davidson LN, Kyne PM, Simpfendorfer CA, Harrison LR, Carlson JK, Fordham SV (2016) Ghosts of the coast: global extinction risk and conservation of sawfishes. Aquat Conserv 26:134-153

Feldheim KA, Gruber SH, Ashley MV (2002) The breeding biology of lemon sharks at a tropical nursery lagoon. Proc R Soc B 269:1655-1661

Feldheim KA, Gruber SH, Ashley MV (2004) Reconstruction of parental microsatellite genotypes female polyandry and philopatry in the lemon shark, Negaprion brevirostris. Evolution 58:2332-2342

* Feldheim KA, Chapman DD, Simpfendorfer CA, Richards VP and others (2010) Genetic tools to support the conservation of the endangered smalltooth sawfish, Pristis pectinata. Conserv Genet Resour 2:105-113

Feldheim KA, Gruber SH, DiBattista JD, Babcock EA and others (2014) Two decades of genetic profiling yields first evidence of natal philopatry and long-term fidelity to parturition sites in sharks. Mol Ecol 23:110-117

* Feutry P, Kyne PM, Pillans RD, Chen X, Marthick J, Morgan DL, Grewe PM (2015) Whole mitogenome sequencing refines population structure of the Critically Endangered sawfish Pristis pristis. Mar Ecol Prog Ser 533:237-244

Fields AT, Feldheim KA, Poulakis GR, Chapman DD (2015) Facultative parthenogenesis in a critically endangered wild vertebrate. Curr Biol 25:R446-R447

* Flowers KI, Ajemian MJ, Bassos-Hull K, Feldheim KA, Hueter RE, Papastamatiou YP, Chapman DD (2016) A review of batoid philopatry with implications for future research and population management. Mar Ecol Prog Ser 562:251-261

*Griffiths AM, Jacoby DMP, Casane D, McHugh M, Croft DP, Genner MJ, Sims DW (2012) First analysis of multiple paternity in an oviparous shark, the small-spotted catshark (Scyliorhinus canicula L.). J Hered 103:166-173

*Harmon TS, Kamerman TY, Corwin AL, Sellas AB (2016) Consecutive parthenogenetic births in a spotted eagle ray, Aetobatus narinari. J Fish Biol 88:741-745

*Heupel MR, Carlson JK, Simpfendorfer CA (2007) Shark nursery areas: concepts, definition, characterization and assumptions. Mar Ecol Prog Ser 337:287-297

*Hueter RE, Heupel MR, Heist EJ, Keeney DB (2004) Evidence of philopatry in sharks and implications for the management of shark fisheries. J Northwest Atl Fish Sci 35:239-247

Jones OR, Wang J (2010) COLONY: a program for parentage and sibship inference from multilocus genotype data. Mol Ecol Resour 10:551-555

Mayr E (1963) Animal species and evolution. Belknap Press, Cambridge, MA

*Mourier J, Planes S (2013) Direct genetic evidence for reproductive philopatry and associated fine-scale migrations in female blacktip reef sharks (Carcharhinus melanopterus) in French Polynesia. Mol Ecol 22:201-214

*Norton SL, Wiley TR, Carlson JK, Frick AL, Poulakis GR, Simpfendorfer CA (2012) Designating critical habitat for juvenile endangered smalltooth sawfish in the United States. Mar Coast Fish 4:473-480

* Phillips NM, Chaplin JA, Morgan DL, Peverell SC (2011) Population genetic structure and genetic diversity of three critically endangered Pristis sawfishes in Australian waters. Mar Biol 158:903-915

*Portnoy DS, Heist EJ (2012) Molecular markers: progress and prospects for understanding reproductive ecology in elasmobranchs. J Fish Biol 80:1120-1140 
Poulakis GR, Stevens PW, Timmers AA, Wiley TR, Simpfendorfer CA (2011) Abiotic affinities and spatiotemporal distribution of the endangered smalltooth sawfish, Pristis pectinata, in a south-western Florida nursery. Mar Freshw Res 62:1165-1177

Poulakis GR, Urakawa H, Stevens PW, DeAngelo JA and others (2017) Sympatric elasmobranchs and fecal samples provide insight into the trophic ecology of the smalltooth sawfish. Endang Species Res 32:491-506

Pratt HL (1993) The storage of spermatozoa in the oviducal glands of western north Atlantic sharks. Environ Biol Fishes 38:139-149

Pratt HL Jr, Carrier JC (2001) A review of elasmobranch reproductive behavior with a case study on the nurse shark, Ginglymostoma cirratum. Environ Biol Fishes 60:157-188

Scharer RM, Patterson WF III, Carlson JK, Poulakis GR (2012) Age and growth of endangered smalltooth sawfish (Pristis pectinata) verified with LA-ICP-MS analysis of vertebrae. PLOS ONE 7:e47850

Scharer RM, Stevens PW, Shea CP, Poulakis GR (in press) All nurseries are not created equal: large-scale habitat

Editorial responsibility: Dean Grubbs (Guest Editor), St. Teresa, Florida, USA use patterns in two smalltooth sawfish nurseries. Endang Species Res, doi:10.3354/esr00871

Simpfendorfer CA, Poulakis GR, O'Donnell PM, Wiley TR (2008) Growth rates of juvenile smalltooth sawfish Pristis pectinata Latham in the western Atlantic. J Fish Biol 72: 711-723

Simpfendorfer CA, Wiley TR, Yeiser BV, Poulakis GR, Stevens PW, Heupel MR (2011) Environmental influences on the spatial ecology of juvenile smalltooth sawfish (Pristis pectinata): results from acoustic monitoring. PLOS ONE 6:e16918

Simpfendorfer CA, Kyne PM, Noble TH, Goldsbury J and others (2016) Environmental DNA detects Critically Endangered largetooth sawfish in the wild. Endang Species Res 30:109-116

* Sunnucks P, Hales DF (1996) Numerous transposed sequences of mitochondrial cytochrome oxidase I-II in aphids of the genus Sitobion (Hemiptera: Aphididae). Mol Biol Evol 13:510-524

* Wang J (2004) Sibship reconstruction from genetic data with typing errors. Genetics 166:1963-1979

Submitted: January 20, 2017; Accepted: October 5, 2017 Proofs received from author(s): December 4, 2017 